\title{
Systematic Analysis of Adenovirus Disinfection as a Model for Testing Emergent and Bioterrorism Agent Inactivation prior to Negative Stain Electron Microscopy
}

\author{
C.D. Humphrey, X. Lu, D. Erdman
}

Division of Viral and Rickettsial Diseases, National Center for Infectious Diseases, Centers for Disease control and Prevention (CDC), Atlanta GA 30333

Electron microscopy (EM) is useful for pathogen identification in bioterrorism (BT) scenarios or for identifying emergent viruses [1]. Negative stain EM provides sufficient detail to identify viruses to a family without having prior knowledge of their identity, even when the agent is fastidious to culture or when it is difficult to obtain infected tissues. Nucleic acid amplification, immunological or in situ hybridization assays may then be used for specific identification [2].

Disinfection protocols for inactivating specimens prior to EM are usually methods extrapolated from common laboratory disinfection protocols. These protocols have often been used without systematic testing under the conditions used for EM. Results obtained with EM procedures may differ from those of typical laboratory disinfection protocols. If appropriate safety precautions are not implemented infectious agents may introduce risks to the investigator and the community. Infectious agents must be rendered harmless for investigation without use of disinfection methods that impair identification or efficient detection. Glutaraldehyde and other common disinfectants have been compared previously for their relative abilities to inactivate virus [3]. Glutaraldehyde inactivated virus without causing structural changes while other disinfectants damaged virus structure. Irradiation including gamma irradiation or UV light has been used successfully to inactivate viruses $[4,5]$. A combination of formaldehyde $(\mathrm{F})$ vapor, followed by $10 \%$ hypochlorite vapor combined with UV irradiation has been suggested for inactivation of variola and herpesvirus [6,7]. Disinfection by mixing an agent with F or paraformaldehyde (PF) also provides safety [8].

Using an adenovirus model we tested various virus inactivation protocols designed for negative stain EM in order to determine their efficacy and efficiency. Adenovirus was chosen because the virus is highly infectious to cell cultures, easily managed within biosafety 2 level guidelines, and has precedence as a test virus for inactivation studies [4,5]. We tested disinfected adenovirus adsorbed grids and adenovirus suspensions mixed with paraformaldehyde by using cell culture infectivity to determine the respective abilities of various disinfection protocols. We also tested microforceps tips used to transfer grids, and filter papers used to blot grids between steps.

Each of the disinfection methods was suitable to inactivate adenovirus (Tables 1-3). Pre-inactivation in tubes prior to virus adsorption is more efficacious than post-adsorption inactivation protocols. None of the inactivation methods impaired recognition of adenovirus, though high paraformaldehyde concentrations ( $8 \%$ or greater) may alter structure. Pre-inactivation with $2-5 \%$ paraformaldehyde does not interfere with the identification of other viruses [9]. Also, virus identification following aldehyde fixation has been used successfully, without incident, by participants in external quality assurance exercises [8]. Microforceps need special attention whenever post virus-adsorption disinfection protocols are used in order to prevent virus from contaminating sequential steps of the inactivation process. As used in this study, UV light alone was sufficient to inactivate adenovirus. 
Unfortunately, issues of dosage control variability and repeatability prohibit recommending UV disinfection alone for virus inactivation in the EM setting. The testing method presented may also be used to test disinfection of viruses other than adenovirus, or to test other disinfection protocols. Adenovirus is highly resistant to inactivation by chemical or physical means. However, a protocol developed for adenovirus may not adequately provide safety, efficacy, and efficiency for doing EM with all infectious agents. It may be necessary to similarly test specific BT agents and emergent agents, or other agents within the same family, in order to develop guidelines for safety, efficacy, and efficiency of EM for their identification.

\section{References}

[1] C. D. Humphrey, Microsc. Microanal. 20039 (Suppl 2) 200.

[2] C. D. Humphrey, Microsc. Microanal. 200410 (Suppl 2) 190.

[3] Rodgers et al 1985 J. Med. Micro. 20 (1985) 123.

[4] S. Sullivan et al., Applied Microbiol. 22 (1971) 61.

[5] K.R. Cameron et al., Arch. Virol. 62 (1979) 31.

[6] C. S. Goldsmith, Microsc. Microanal. 10 (Suppl 2) (2004) 188.

[7] http://www.bt.cdc.gov/labissues/index.asp.

[8] S.S. Biel and H.R. Gelderblom, J. Clin. Virol. 13 (1999) 105.

[9] C. D. Humphrey, personal observation.

Table 1. Adenovirus on Grids: drop-to-drop method, post grid adsorption inactivation with paraformaldehyde immersion

\begin{tabular}{|l|l|l|l|}
\hline $\begin{array}{l}\text { a } 4 \% \text { PF } \\
\text { imm. 5m ea. side }\end{array}$ & $\begin{array}{l}{ }^{\mathrm{b}} 4 \% \text { PF } \\
\text { imm. 30s ea. side }\end{array}$ & $\begin{array}{l}{ }^{\mathrm{bc}} 2.5 \%-8 \% \text { PF, } 5 \mathrm{~m}- \\
10 \mathrm{~m} \text { imm. ea. side }\end{array}$ & ${ }^{\mathrm{b}}$ No PF \\
\hline${ }^{\mathrm{d}} 4 / 4+$ & $1 / 1+$ & $\mathbf{0} / 22+$ & $7 / 7+$ \\
\hline
\end{tabular}

a $\mathbf{7 0 \%}$ ethanol only wipe of microforceps between steps, dry tissue wipe

${ }^{\mathrm{b}}$ Immerse microforceps $5 \mathrm{~min}$. ea in 10\% bleach, 5\% PF, $70 \%$ ethanol, dry tissue wipe

${ }^{\mathrm{c}} 3-4$ grids each test ${ }^{\mathrm{d}}$ Num. $=$ No. of spec. grids det. infectious, den. $=$ No. of grids tested

Table 2. Adenovirus on Grids: drop-to-drop method, post grid adsorption inactivation by formaldehyde vapor, $\mathbf{1 0 \%}$ bleach vapor, UV irradiation

\begin{tabular}{|l|l|l|}
\hline $\begin{array}{l}\text { a } 37 \% \text { F vapor, 10\% bleach } \\
\text { vapor, UV light singly or } \\
\text { combined, 2-3 grids ea. test }\end{array}$ & $\begin{array}{l}\text { b } 37 \% \text { F vapor, 10\% bleach } \\
\text { vapor, UV light singly, or } \\
\text { combined, 2-3 grids ea. test }\end{array}$ & \\
\hline${ }^{\mathrm{c}} 1 / 8+$ & $\mathbf{0} / 11+$ & $2 / 2+$ \\
\hline
\end{tabular}

a $70 \%$ ethanol wipe of microforceps between steps, dry tissue wipe

${ }^{\mathrm{b}}$ Immerse microforceps $5 \mathrm{~min}$. ea in 10\% bleach, 5\%PF, $70 \%$ ethanol, dry tissue wipe

${ }^{\mathrm{c}}$ Numerator $=$ No. of spec. grids det. infectious, denominator $=$ No. of grids tested

Table 3. Inactivation of adenovirus in tubes prior to application of virus to grids; mixed 1:1 with paraformaldehyde or buffer

\begin{tabular}{|l|l|l|l|l|}
\hline${ }^{\mathrm{a}} 5 \%$ PF & ${ }^{\mathrm{b}} 16 \%$ PF & ${ }^{\mathrm{bc}} 5-8 \%$ PF & No Inactivation & Buffer Control \\
\hline${ }^{* \mathrm{~d}} 9 / 9+$ & $* 4 / 4+$ & $\mathbf{0} / 8+$ & $1 / 1+$ & $\mathbf{0} / 1+$ \\
\hline
\end{tabular}

${ }^{a}$ no rinse after initial incub., ${ }^{b}$ rinse after initial incub., ${ }^{c} 4$ grids each test, ${ }^{*}$ cytotoxic effect

${ }^{\mathrm{d}}$ Numerator $=$ No. of spec. tubes det. infectious, denominator $=$ No. of spec. tubes tested 